\title{
Sonlu Elemanlara Dayalı Dinamik Analiz; Zemin İyileştirme - Derin Temel Örneği
}

\author{
${ }^{1}$ Hüseyin MUNGAN, ${ }^{* 2}$ Ayşe Bengü SÜNBÜL \\ ${ }^{1}$ Zonguldak MYO, Zonguldak Bülent Ecevit Üniversitesi, Türkiye \\ *2İnşaat Mühendisliği Bölümü, Zonguldak Bülent Ecevit Üniversitesi, Türkiye
}

\section{Özet}

Bu çalışmada deprem etkisi altında bir yapının, depremin merkez üssüne olan mesafesinin uzak ve yakın olması durumunun davranışa etkisi incelenmektedir. Bu amaçla sonlu eleman modeli oluşturulan yumuşak zemin ortamındaki $17 \mathrm{~m}$ genişliğinde ve $19 \mathrm{~m}$ boyundaki yayılı temel, üst yapıdan yayılı temele aktarılan $100 \mathrm{kPa}$ ile düzlemsel şekil değiştirme esası ile 15 düğüm noktalı elemanlarla modellenmiştir.

Modele iki farklı zemin iyileştirme yöntemi (darbeli kırmataş kolon (DKK) ve Jet Grout kolonu) uygulanarak düşey yer değiştirmeleri (oturmaları), derin temel uygulaması (delme kazık) ile değerlendirilmiştir.

Yapılan model analiz sonuçlarına göre; statik durumda düşey yer değiştirme değerlendirildiğinde, en iyi performans derin temel olan delme kazık uygulamasında elde edilmiştir. Analizler dinamik durumda tekrarlandığında; depremin gerçekleştiği bölgede Jet Grout kolonu, DKK ve Delme kazık uygulamasında; yayılı temel altında yatay yer değiştirme değeri $\left(\mathrm{U}_{\mathrm{x}}\right)$, uzak deprem durumunda daha yüksek elde edilmektedir. Aynı zamanda delme kazık uygulanmış modelin dinamik durum performansının DKK ve Jet Grout kolonuna göre daha iyi olduğu modelde gözlenmiştir.

Anahtar Kelimeler: DKK, Jet Grout kolonu, delme kazık, sonlu eleman metodu.

\begin{abstract}
In this study, the effect of a structure under the effect of earthquake on the behavior of the distance to the epicenter of the epicenter is investigated. For this purpose, the base with $17 \mathrm{~m}$ width and 19 $\mathrm{m}$ length in the soft ground environment where the finite element model is formed is modeled with 15 node points elements with the planar deformation principle with $100 \mathrm{kPa}$ transferred from the upper structure.

The model was evaluated by two different soil remediation methods (Rammed aggregate piers (RAP) and Jet Grout column), vertical displacement (settle), deep foundation application (drilling pile).

According to the model analysis results; When vertical displacement is assessed in the static case, the best performance is obtained in deep pile drilling practice. When the analyzes are replicated in the dynamic state; Jet Grout, RAP and Drilling pile application in the region where depression occurs; the horizontal displacement, $\left(\mathrm{U}_{\mathrm{x}}\right)$ value under the spread foundation is higher as the earthquake moves away from the center of the earth. At the same time, it was observed that the dynamic state performance of the model with drilled piles was better than the RAP and Jet Grout columns.
\end{abstract}

Key Words : RAP, Jetgrout column, drilling pile, finite element method. 


\section{Giriş}

Günümüz geoteknik modelleme çalışmalarında hem statik hem dinamik durum için zemin ve yapı birlikte analiz edilerek, depreme dayanıklı yapı tasarımı konusunda daha doğru hesaplar yapılması sağlanmaktadır. Bu çalışmada, hem statik hem de dinamik yükler altında zeminlerin gerilme-şekil değiştirme ilişkisi ve deformasyon özellikleri sonlu eleman modellerinde analiz edilerek gerçekçi sonuçlara ulaşılması hedeflenmiştir. Çalışmada, Aydın İli Germencik ilçesindeki Jeotermal Enerji Santrali zemin etüdü raporundaki geoteknik veriler kullanılarak, elverişsiz zemin koşullarında, rijit kolonların statik ve dinamik davranışları sonlu elemanlar yazılımı olan Plaxis 2D programında analiz edilmiştir.

\section{Rijit Kolonlar}

\subsection{Darbeli Kırmataş Kolonlar (DKK)}

Taş kolon yöntemi 1930' lu yıllarda Almanya'da ortaya çıkmış olup, Türkiye'de son 10 yıl içerisinde kullanılmaya başlanmıştır. Türkiye'de ilk defa taş kolon uygulaması zemin iyileştirme kapsamında kullanılmış olup, dane boyutu 10-100 mm arasında değişen ince dane oran $1 \% 5$ ' ten az olan ve ortamla kimyasal reaksiyona girmeyen doğal kırmataş malzemesi olarak kullanılmıştır [1]. Taş kolonlar zemin rijitliğini artırmak için yapılan diğer yöntemlere göre daha hızlı ve ekonomik olan zemin iyileştirme yöntemidir. Ayrıca deprem sırasında da fazla boşluksuyu basınçlarını sönümlemektedir [2]. Zeminde rijitliği artırmak için yapılan taş kolonlar, deprem sırasında yatay ve düşey deplasmanları da azaltmaktadır [3].

DKK yönteminde, diğer taş kolon yapım yöntemlerinden farklı olarak, granüler malzeme vurularak sıkıştırılır ve rijit bir kolon elde edilir. DKK, yöntemlerinden günümüzde en çok olarak kullanılan yöntemler, Geopier ${ }^{\circledR}$ ve Impact $^{\circledR}$ DKK yöntemleridir.

Bu çalışmada uygulanan yöntem Impact ${ }^{\circledR}$ yönteminde Şekil 1.' de görüldüğü gibi zemine 36 cm çaplı mandrel istenilen derinliğe indirilerek, içine iyi derecelenmiş doğal kırmataşlar doldurulur. Daha sonra mandrel $1 \mathrm{~m}$ yukarı kaldırılır $67 \mathrm{~cm}$ aşağıya indirilerek, tokmakla kırmataşlar sıkıştırılır. Sıkıştırma sonucunda $36 \mathrm{~cm}$ olan çap değeri $50 \mathrm{~cm}$ olarak $33 \mathrm{~cm}$ ' lik tabaka kalınlığg elde edilir. Kademeli olarak bu işlem zemin yüzeyine kadar devam eder, her kademede 50 cm' lik kolon çapları ve 33 cm' lik tabaka kalınlığı oluşur.

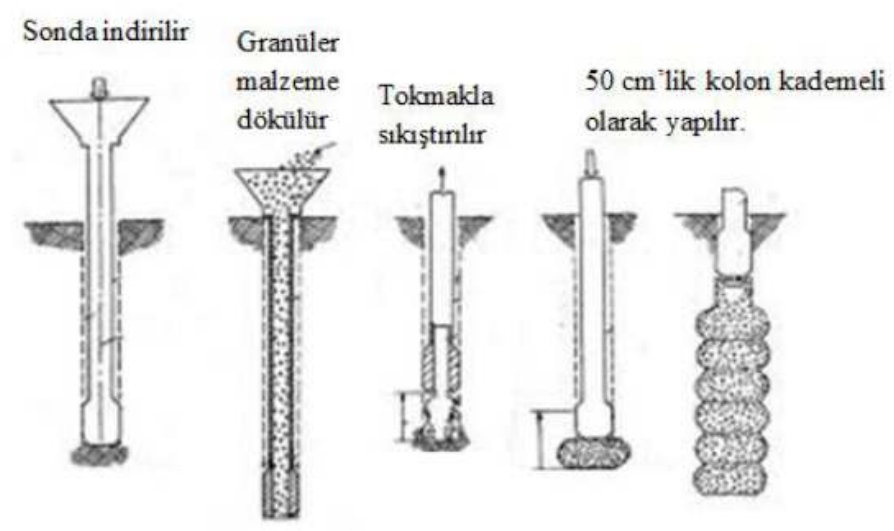

Şekil 1. Impact yöntemi 


\subsection{Jet Grout}

Jet Grout tekniğinde, zeminde istenilen derinliğe kadar sonda ile delinerek örselendikten sonra sondanın yukarıya doğru çekilmesiyle, sondanın ucundan $3 \mathrm{~mm}$ çaplı bir memeden yüksek basınçla su ve çimento birlikte verilerek, zemin içinde kolon oluşturulan zemin iyileştirme türüdür (Şekil 2.). Su/çimento oranı genel olarak 1/1 dir. Priz alma süresinin uzun olması istenilen dayanımı almak için genellikle su ve çimento ile birlikte katkı maddeleri de verilmektedir.

Jet Grout yöntemi zemin iyileştirmelerinin yanı sıra, temel altı yatak oluşturulması, tünel korumada, kazı desteklenmesinde ve yanal itki azaltmada da kullanılan bir yöntemdir. Zeminin ortamında taşıma gücünü arttırarak oturmaları azaltmaktadır [4].

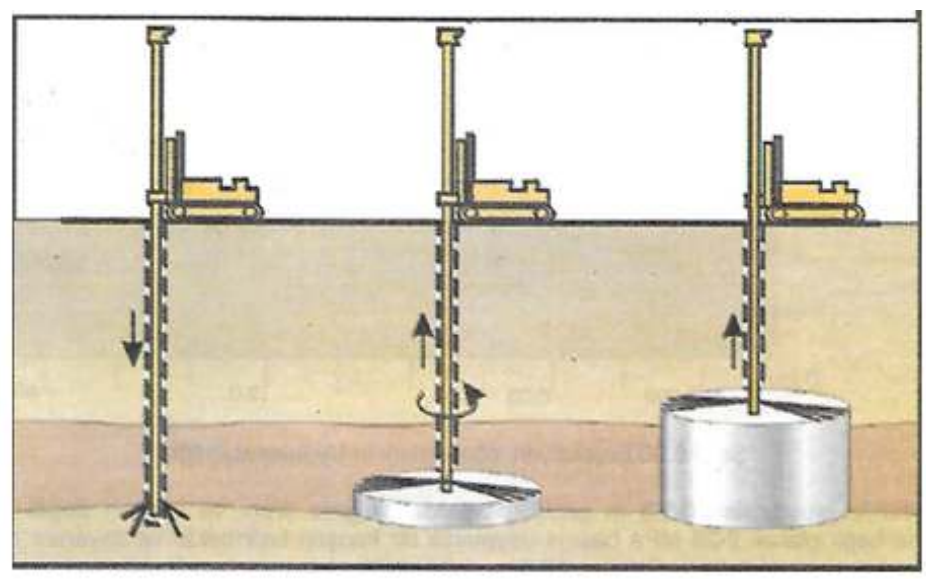

Şekil 2. Jet Grout yöntemi [5]

\subsection{Delme Kazıklar}

Delme kazıklar, grup halinde yapılıp aşırı yüklerin olduğu ve aşırı oturmaların görüldüğü zeminlerde, zemin iyileștirme yöntemlerinin yeterli olmadığı durumda kullanılır. Kazıklı temellerde amaç; yapı yüklerini sağlam derin tabakalara iletebilmektir. Kazıklar imal edilen malzeme türüne göre, ahşap, çelik ve betonarme olabilirler.

Kazık seçimi yapılırken, zemin türü, yükler çaplar ve kazık boyu dikkate alınmalıdır [6]. Kullanım tipine göre, uç kazığı, sürtünme kazığı, çekme kazığı ve sıkıştırma kazığı olarak farklı tipte kazıklar mevcuttur. Kazıklar yapım yöntemlerine göre şu şekilde sıralanır:

a) Delme Kazıklar

b) Çakma Kazıklar

c) Vidalamalı Kazıklar

d) Enjeksiyonlu Kazıklar

Çalışmada, delme kazıklar üzerinde durulmuş olup, açılan silindirik bir çukur içerisine konulan donatıların betonlanması suretiyle elde edilirler [6]. Şekil 3.' te görüldüğü gibi 
zemine açılan kuyuya donatılar yerleştirilir daha sonra beton dökülerek delme kazık imalatı tamamlanir.

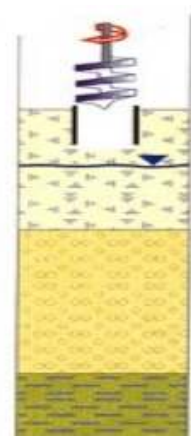

Ön Delgi

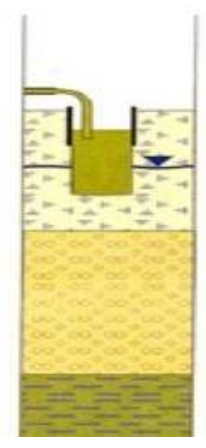

Kuyu İçi Stabilite

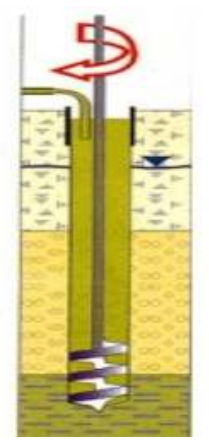

Delgi

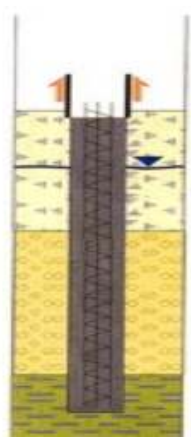

Donatı Montaj1

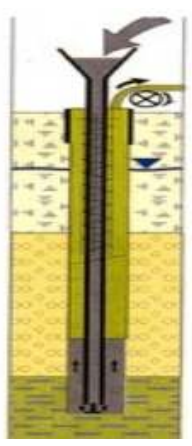

Betonaj

Şekil 3. Delme kazık yapımı

\section{Sayısal Model}

Bu çalışmada kullanılan, Plaxis 2D programı geoteknik mühendisliği problemlerinin analizi için geliştirilmiş bir sonlu elemanlar yazılımıdır. Yazılım, analizlerde gerilme artışları ve ani oturmaların hesaplanmasında elasto-plastik davranış teorisini esas almaktadır. Yazılımda zemin ortamı iki fazlı (katı ve sıvı), olarak göz önüne alınarak drenajlı veya drenajsız çözümler yapılabilmektedir [7].

\subsection{Sonlu Elemanlar Yöntemi}

Sonlu elemanlar nümerik analiz yöntemi, matematiksel ifadelerle tanımlanan sürekli problemlerin genel çözüm yöntemi olarak tanımlanmıştır [8]. Ayrıca sonlu elemanlar yöntemi, sayısal yöntemlerin genelde mühendislik problemlerine ve özelde geoteknik problemlerine uygulanması ile ilgili birçok çalışma mevcuttur $[9,10,11,12,13]$. Plaxis 2D iki boyutlu deformasyon analizi ve geoteknik mühendisliği stabilite analizlerinde sonlu elemanlar yöntemi ile çözüm üreten bir programdır [14]. Yap1 ve zemin arasında kesişim modeli oluşturulmasına imkan sağlar. Plaxis üzerinde yer alan dinamik modül ise zeminleri analiz eder ve deprem gibi dinamik yükleme etkisinde kalmış yapıların analizini mümkün k1lar.

\section{Analiz}

Çalışmada programda 4 farklı zemin tabakası tanımlanarak, düzlem deformasyon (Plane Strain) modeli kullanılarak analizler yapılmıştır (Şekil 4). Analizlerde zeminin, gerilme deformasyon davranışını hiperbol olarak tanımlayıp, 3 farklı elastisite modülünü esas alan ve zeminin elastoplastik özelliğini daha iyi ifade etmesinden ötürü pekleşen zemin modeli, (Hardening Soil) kullanılarak tüm analizler drenajlı durumda yapılmıştır. Yeraltı su seviyesi zemin yüzeyinden $1.7 \mathrm{~m}$ aşağıdadır. Analizlerde kullanılan zemin parametreleri ve yayılı temel parametreleri Tablo 1. ve Tablo 2.' de verilmiştir. 


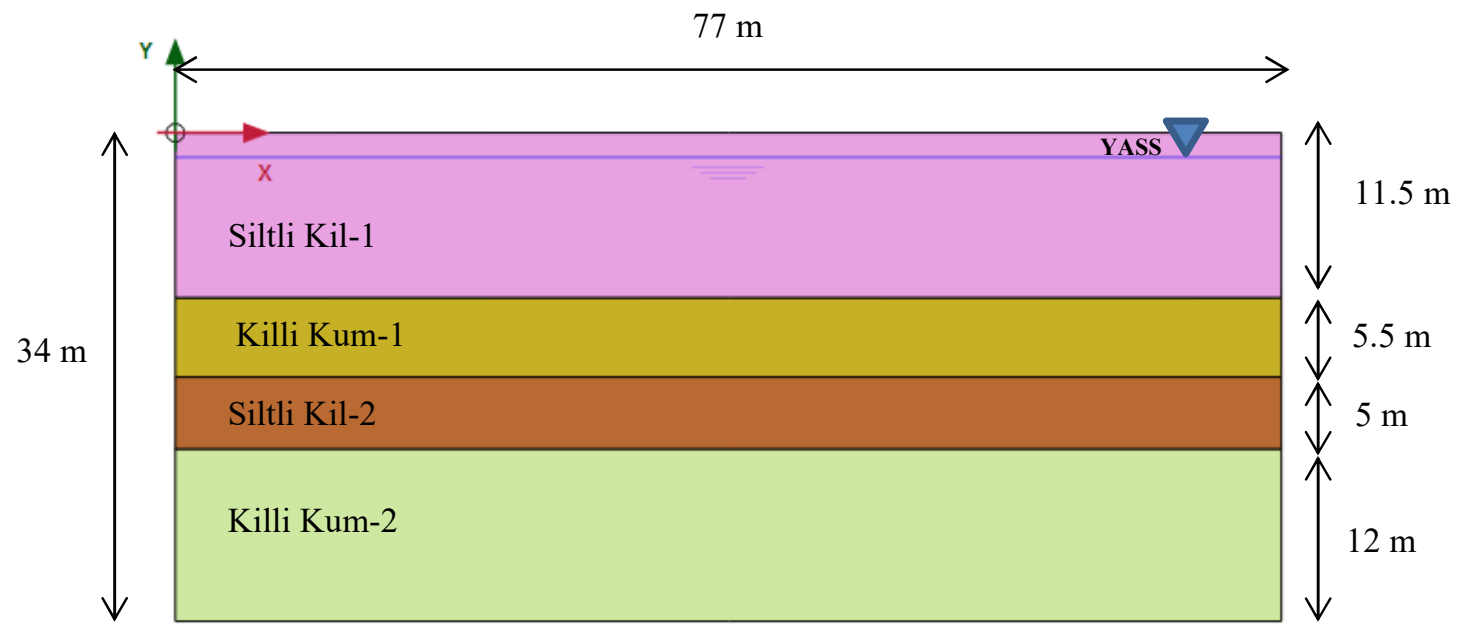

Şekil 4. Plaxis 2D programında zemin tabakalarının modellenmesi

Tablo 1. Analizde Kullanılan Zemin Parametreleri

\begin{tabular}{|l|c|c|c|c|}
\hline & Siltli Kil-1 & Kili Kum-1 & Siltli Kil-2 & Killi Kum-2 \\
\hline Malzeme Modeli & Pekleşen Zemin & Pekleşen Zemin & Pekleşen Zemin & Pekleşen Zemin \\
\hline Drenaj Durumu & Drenajlı & Drenajlı & Drenajlı & Drenajlı \\
\hline$\rho_{\mathrm{n}}\left(\mathrm{kN} / \mathrm{m}^{3}\right)$ & 18 & 19 & 18 & 19 \\
\hline$\rho_{\text {sat }}\left(\mathrm{kN} / \mathrm{m}^{3}\right)$ & 19 & 20 & 19 & 20 \\
\hline $\mathrm{E}_{50^{r e f}}(\mathrm{kPa})$ & 2773 & 16800 & 6240 & 20000 \\
\hline $\mathrm{E}_{\text {oed }}{ }^{\text {ref }}(\mathrm{kPa})$ & 2773 & 16800 & 6240 & 20000 \\
\hline $\mathrm{E}_{\text {ur }}{ }^{\text {ref }}(\mathrm{kPa})$ & 8319 & 50400 & 18720 & 60000 \\
\hline$v^{\prime}{ }_{\text {ur }}$ & 0.2 & 0.2 & 0.2 & 0.2 \\
\hline $\mathrm{c}^{\prime}(\mathrm{kPa})$ & 10 & 5 & 23 & 10 \\
\hline$\phi^{\prime}\left({ }^{\circ}\right)$ & 25 & 35 & 20 & 33 \\
\hline$\Psi\left(^{\circ}\right)$ & 0 & 5 & 0 & 3 \\
\hline
\end{tabular}

Tablo 2. Analizde Kullanılan Yayılı Temel Özellikleri

\begin{tabular}{|c|c|c|c|c|c|}
\hline Malzeme & Malzeme Modeli & Drenaj Durumu & $\rho\left(\mathrm{kN} / \mathrm{m}^{3}\right)$ & $\mathrm{E}(\mathrm{GPa})$ & $v$ \\
\hline Yayılı Temel & Lineer Elastik & Geçirimsiz & 24 & 30 & 0.2 \\
\hline
\end{tabular}

\subsection{Statik Durumda Rijit Kolonlar Altında Yayılı Temeldeki Oturmalar}

$\mathrm{Bu}$ yöntemde yayılı temel altına $1.7 \mathrm{~m}$ aralıklarla $17 \mathrm{~m}$ uzunluğunda, DKK, Jet Grout ve Delme Kazık kolon grupları tanımlanmıştır (sırasıyla şekil 5,6,7). Plaxis 2D programında kolonlar arasında mesafe tanımlaması yapılabilen embedded beam row özelliği kullanılarak, Tablo 3.' teki parametreler tanımlanmıştır. 
Tablo 3. Rijit Kolon Parametreleri

\begin{tabular}{|c|c|c|c|c|c|}
\hline Malzeme & E (MPa) & $\rho\left(\mathrm{kN} / \mathrm{m}^{3}\right)$ & Çap $(\mathrm{m})$ & $\begin{array}{c}\text { Sürtünme Direnci } \\
\mathrm{f}_{\mathrm{s}}(\mathrm{kN} / \mathrm{m})\end{array}$ & $\begin{array}{c}\text { Uç Direnci } \\
\mathrm{Q}_{\mathrm{g}}(\mathrm{kN})\end{array}$ \\
\hline DKK & 165 & 22 & 0.5 & 65 & 229 \\
Jet Grout & 300 & 24 & 0.6 & 784.3 & 229 \\
$\begin{array}{c}\text { Delme } \\
\text { Kazık }\end{array}$ & 300000 & 24 & 0.6 & 784.3 & \\
\hline
\end{tabular}

Kademeli olarak modellenen yayılı temelde, $100 \mathrm{kPa}$ yayılı yük altında Şekil 5. ve Şekil 6. ve Şekil 7.' de görüldüğ̈̈ gibi sırasıyla DKK' 11, Jet Grout' lu ve Delme Kazıklı ortamda toplamda $27.56 \mathrm{~cm}, 19.11 \mathrm{~cm}$ ve $7.3 \mathrm{~cm}$ oturma görülmüştür.

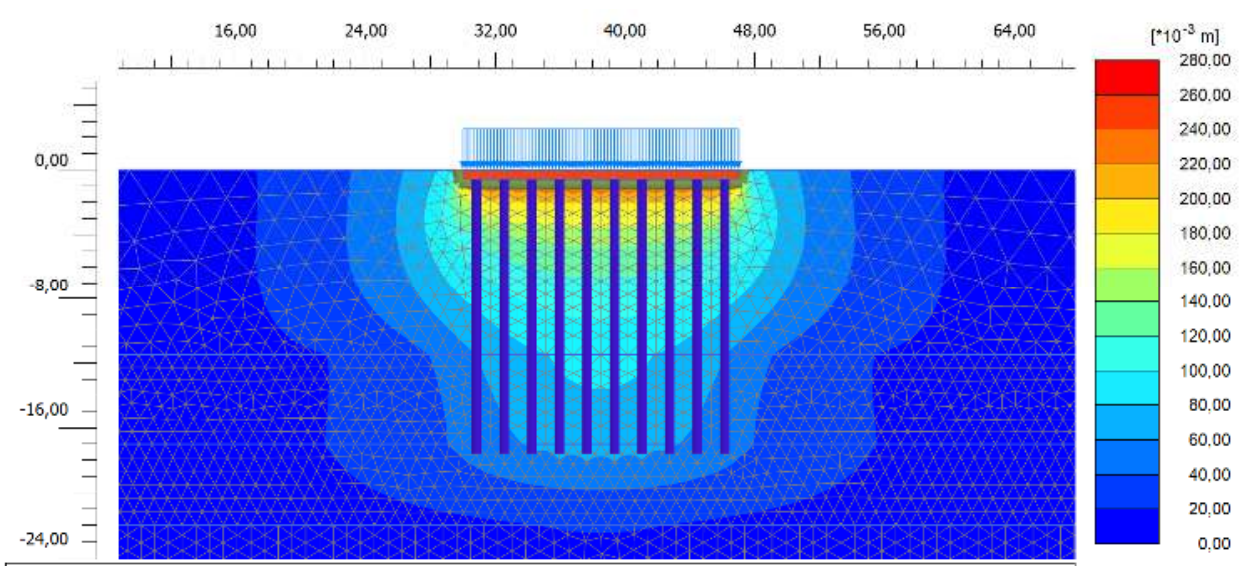

Şekil 5. DKK' lı ortamda yayılı temelde oturma [15]

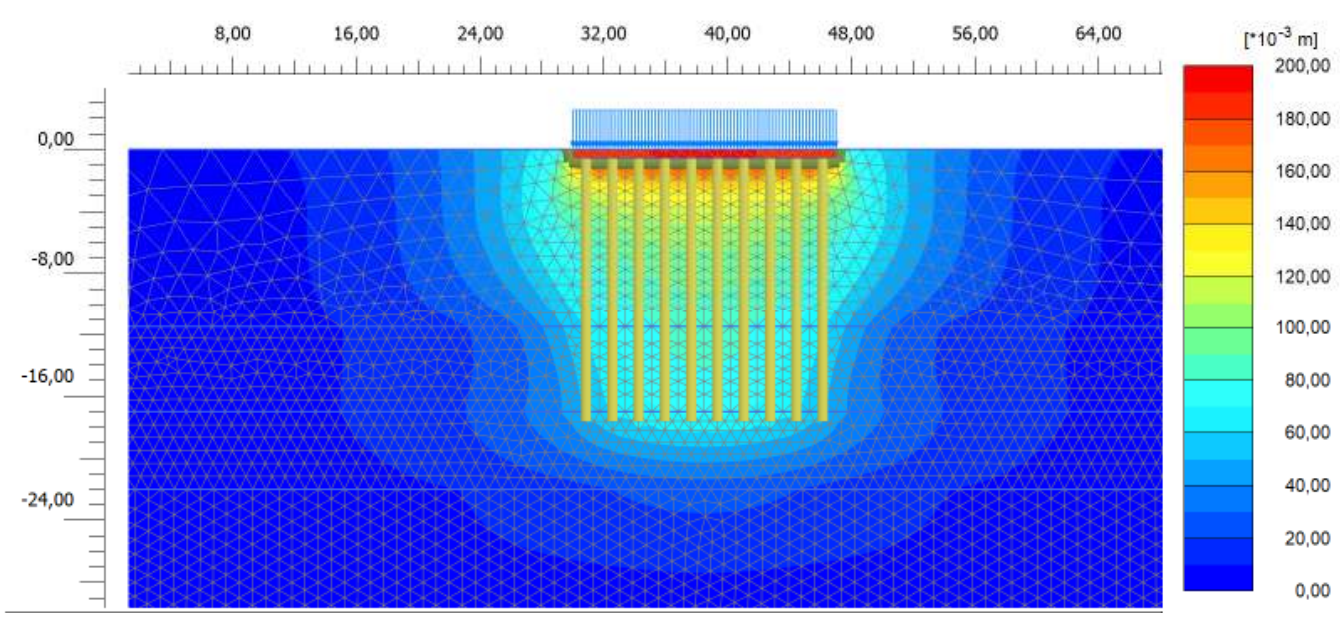

Şekil 6. Jet Grout' lu ortamda yayılı temelde oturma 


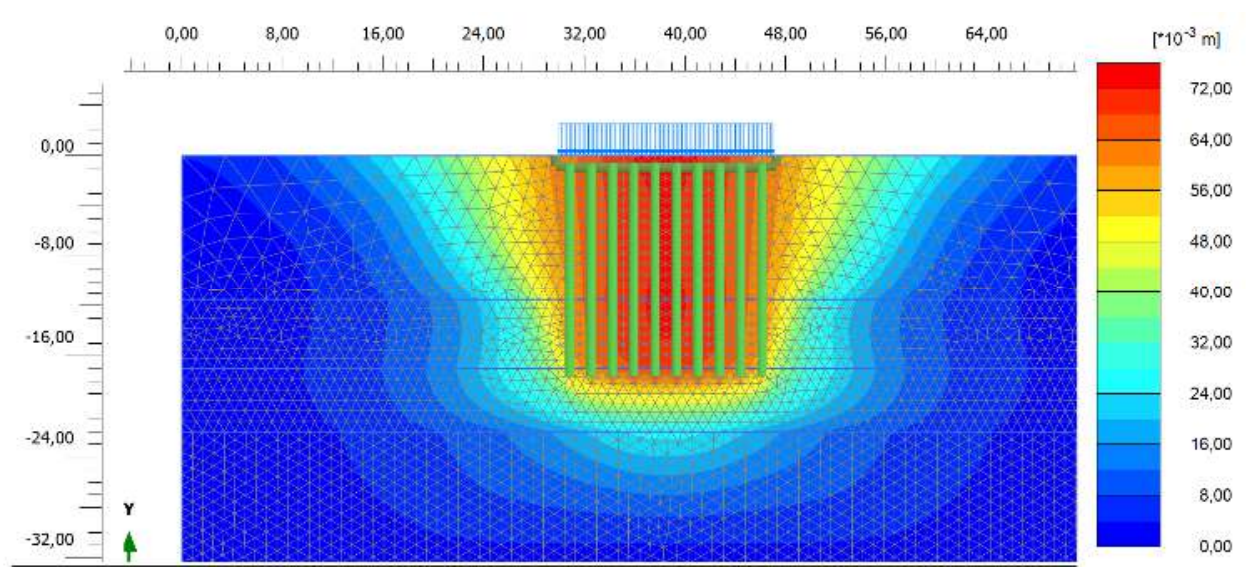

Şekil 7. Delme Kazık’ lı ortamda yayılı temelde oturma

\subsection{Dinamik Durumda Rijit Kolonlar Altında Yayılı Temeldeki Oturmalar}

Dinamik durum incelendiğinde, Şekil 8.' de sirasıyla, tablo 4a. ve tablo 4b.' de $7.1 \mathrm{Mw}$ moment büyüklügündeki deprem kaynağına uzak ve yakın durumda rijit kolonların performansları incelenmiştir.

Deprem süresi her iki durum için 20 saniye olup, yayılı temelin orta noktası referans alınarak, DKK, Jet grout ve Delme kazıklı ortamdaki uzak yakın deprem etkisinin performansları incelendiğinde; sırasıyla DKK, Jet Grout ve Delme Kazıkların depremin uzak ve yakın etkisinde yatay yer değiştirme değerleri, $\left(U_{x}\right)$ görülmektedir (Şekil 8 a.,b.,c.' de). DKK' da depreme uzak durumda maksimum yatay yer değiştirme $30 \mathrm{~cm}$, depreme yakın durumda maksimum yatay yer değiştirme $10 \mathrm{cmdir}$. Jet Grout kolonu için depreme uzak durumda maksimum yatay yer değiştirme $32 \mathrm{~cm}$, depreme yakın durumda maksimum yatay yer değiştirme 10 cmdir. Son olarak delme kazık uygulaması için; depremin uzak olması durumu için maksimum yatay yer değiştirme $27 \mathrm{~cm}$, yakın durumda maksimum yatay yer değiştirme 10 cmdir. Şekil 9a. ve 9b deprem süresince tüm rijit kolonlarda yatay yer değiştirme değerleri, $\left(U_{\mathrm{x}}\right)$ kıyaslandığında yakın ve uzak deprem durumunda en iyi performansı delme kazıklar vermiştir. Ayrıca yatay yer değiştirme değeri, deprem kaynağından uzaklaştıkça daha yüksek elde edilmektedir.

a.

\begin{tabular}{|l|c|}
\hline Yakın Deprem & Loma Prieta (1989) \\
\hline Büyüklük & $7.1 \mathrm{Mw}$ \\
\hline Deprem İstasyonu & Anderson Dam \\
\hline Episantr Uzaklığı & $20.03 \mathrm{~km}$ \\
\hline
\end{tabular}

Tablo 4. Yakın uzak deprem verileri

b.

\begin{tabular}{|l|c|}
\hline Uzak Deprem & Loma Prieta (1989) \\
\hline Büyüklük & $7.1 \mathrm{Mw}$ \\
\hline Deprem İstasyonu & Emeryville \\
\hline Episantr Uzakıı̆̆ı & $81.09 \mathrm{~km}$ \\
\hline
\end{tabular}



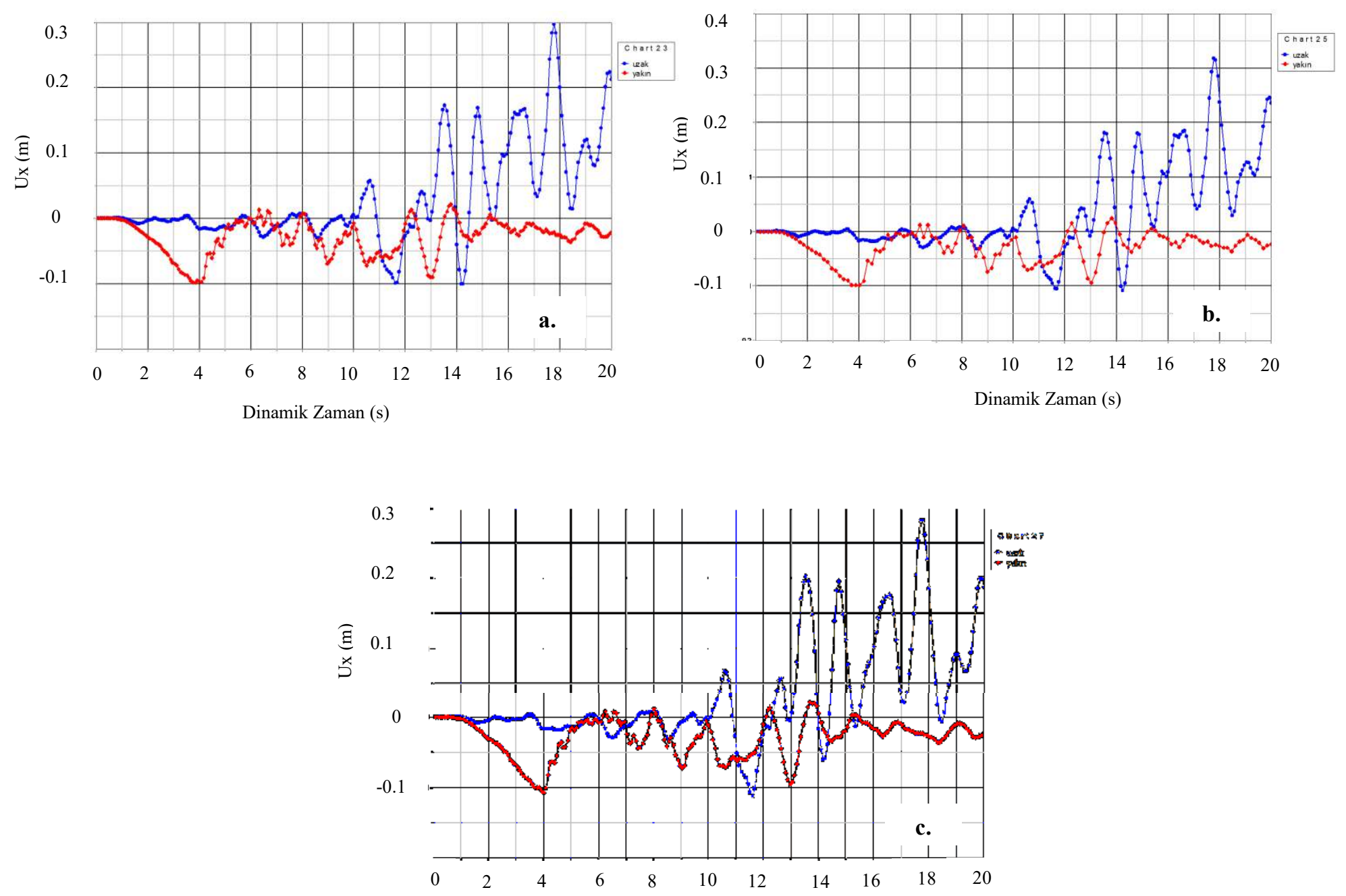

Şekil 8. DKK, Jet Grout ve Delme Kazıkların uzak yakın deprem etkisi altında yatay yerdeğiştirme değerleri
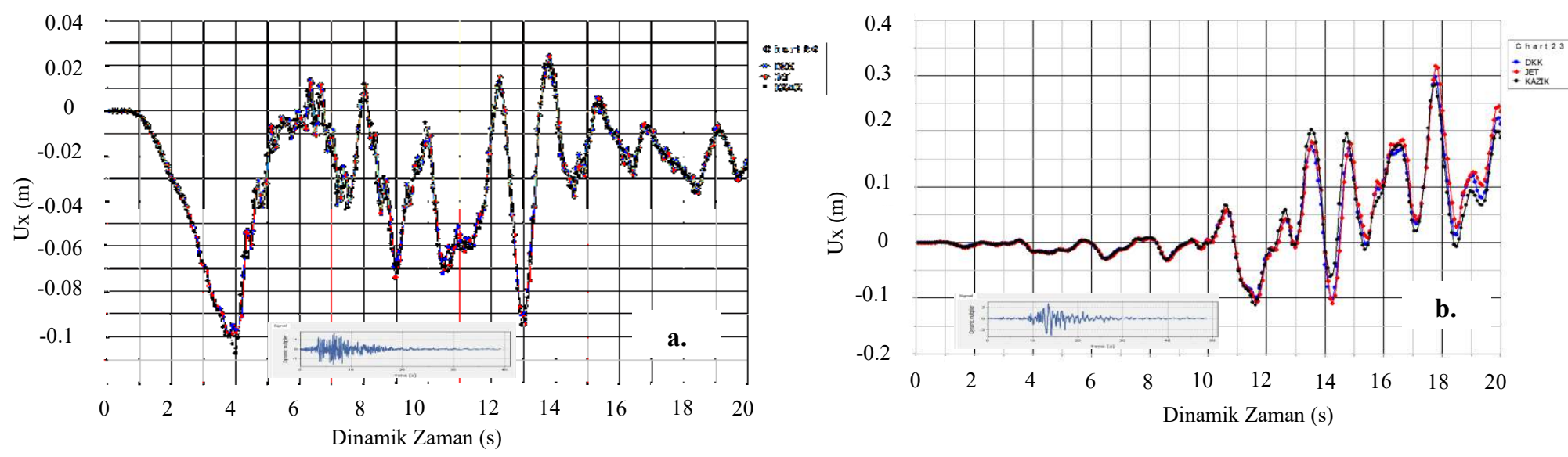

Şekil 9. Rijit kolonların yatay yerdeğiştirme değerleri 


\section{Sonuçlar}

Bu çalışmada zemine rijitlik sağlamak ve oturmaları azaltmak amacıyla zeminlere uygulanan rijit kolonların performansı incelenmiştir. DKK, Jet Grout ve Delme Kazık kolonları aşırı oturmaların görüldüğü zeminlerde oturmaları azaltmaktadır. Statik durumda, DKK' 11 ortamda $27.06 \mathrm{~cm}$ oturma görülmüsşür. Jet Grout kolon ortamında $19.11 \mathrm{~cm}$ oturma görülmüsstür. Delme Kazıklı uygulanmış ortamda $7.3 \mathrm{~cm}$ oturma görülmüştür.

Yapılan model analiz sonuçlarına göre; statik durumda düşey yer değiştirme değerlendirildiğinde, en iyi performans derin temel olan delme kazık uygulamasında elde edilmiştir.

Analizler dinamik durumda tekrarlandığında; depremin gerçekleştiği bölgede DKK, Jet Grout ve Delme kazık uygulamasında; yayılı temel altında yatay yer değiştirme değeri, $\left(U_{\mathrm{x}}\right)$ uzak deprem etkisinde daha yüksek elde edilmektedir. DKK' da uzak durum ile yakın durum arasındaki yatay yer değiştirme farkı \%66 dir. Jet Grout' ta uzak durum ile yakın durum arasındaki yatay yer değiştirme farkı \%68 dir. Delme Kazıkta uzak durum ile yakın durum arasındaki yatay yer değiştirme farkı \%62 dir. Aynı zamanda delme kazık uygulanmış modelin dinamik durum performansının DKK ve Jet Grout kolonuna göre daha iyi olduğu analizlerde görülmüştür.

Statik ve dinamik durumda oturma performansları bakımından, Delme Kazık Kolonları, DKK ve Jet Grout kolonlarına göre daha avantajlıdır. Söz konusu kıyaslama yapılırken, zemin ortamında göstereceği performanslar dikkate alınmalı ayrıca kolonların imalat hızı, maliyeti ve imalat süreleri de dikkate alınarak gerçek kıyaslama yapılmalıdır. Ayrıca tasarım yapılırken, analizlerde beklenilen durumların arazideki uyumluluğu kontrol edilmelidir. Aşırı oturmaların görüldüğü zemin koşullarında zemin iyileştirme yöntemi olarak her üç yöntemde başarılı sonuçlar vermektedir.

\section{Referanslar}

[1] Durgunoğlu H.T, Kulaç F, İkiz S, Karadayılar T. Taş kolonlar ile zemin islahı üzerine bir uygulama, Zemin Mekaniği Ve Temel Mühendisliği Dördüncü Ulusal Kongresi 1992; İTÜ

[2] Selçuk L. Zemin sıvılaşmasına karşı optimum taş kolon tasarımının sonlu elemanlar yöntemi ile modellenmesi, Ankara Üniversitesi Doktora Tezi 2009; Ankara.

[3] Kanmaz H. Rijit kolonların farklı zemin ortamlarındaki performansları, İstanbul Kültür Üniversitesi Fen Bilimleri Enstitüsü Yüksek Lisans Tezi 2014; İstanbul.

[4] Kusin, C. Jet grout yöntemi ile iyileştirilen zeminlerin sonlu elemanlar yöntemiyle sayisal analizi, İnşaat Mühendisliği Anabilim Dali, Çukurova Üniversitesi Fen Bilimleri Enstitüsü, Yüksek Lisans Tezi 2009; Adana.

[5] Önalp A, Sert S. Geoteknik Bilgisi III, Birsen Yayınevi 2010.

[6] Toğrol E, Tan O. Kazıklı Temeller, Birsen Yayıncılık, ISBN 978-975-511-327-4, 2009; Istanbul. 
[7] PLAXIS, User Manual. 2D, (Edited by Brinkgreeve, R.J.B.), Delft University of Technology\& PLAXIS, 2002; The Netherlands.

[8] Zienkiewicz O. C. The finite element method. Maidenhead, England: 1977; McGrawHill.

[9] Cai F, Ugai K. Numerical analysis of the stability of a landslide reinforced with piles. Soils and Foundations, 2000, 40, (1), 73-84.10.3208/sandf.40.73.

[10] Chen TC, Lin ML, Wang KL. Landslide seismic signal recognition and mobility for an earthquake-induced rockslide in Tsaoling, Taiwan. Eng 2014; Geol 171:31-44

[11] Ling H, Ling HI. Kawabata T. Revisiting Nigawa landslide of the 1995 Kobe earthquake. 2014; Geotechnique 64:400-404.

[12] Savage WZ, Baum RL, Morrissey MM, Arndt BPi Finite-element analysis of the Woodway landslide 2000; Washington. U.S. Geological Survey Bulletin 2180.

[13] Griffiths, Lane D.V. Griffiths, P.A. LaneSlope stability analysis by finite elements Geotechnique 1999; pp. 387-403

[14] Brinkgreve R.B.J， Broere W，Waterman D. PLAXIS 2D Dynamic Modüle 2007; Manual Delft University of Technology, Delft

[15] Mungan H. Ground improvement with aggregate piers, Istanbul Kultur University, 2016; Institute of Science and Technology. 